\title{
Cardiovascular effects of basal insulins
}

This article was published in the following Dove Press journal:

Drug, Healthcare and Patient Safety

10 July 2015

Number of times this article has been viewed

\section{Edoardo Mannucci' \\ Stefano Giannini \\ Ilaria Dicembrini'}

'Diabetes Agency, Careggi Teaching Hospital, Florence, ${ }^{2}$ Section of Endocrinology, Department of Biomedical Clinical and Experimental Sciences, University of Florence and Careggi University Hospital, Florence, Italy
Correspondence: Edoardo Mannucci

Diabetes Agency, Careggi

Teaching Hospital, Azienda

Ospedaliero-Universitaria Careggi,

Via delle Oblate 4, Florence 50I4I, Italy

Email edoardo.mannucci@unifi.it
Abstract: Basal insulin is an important component of treatment for both type 1 and type 2 diabetes. One of the principal aims of treatment in patients with diabetes is the prevention of diabetic complications, including cardiovascular disease. There is some evidence, although controversial, that attainment of good glycemic control reduces long-term cardiovascular risk in both type 1 and type 2 diabetes. The aim of this review is to provide an overview of the potential cardiovascular safety of the different available preparations of basal insulin. Current basal insulin (neutral protamine Hagedorn [NPH], or isophane) and basal insulin analogs (glargine, detemir, and the more recent degludec) differ essentially by various measures of pharmacokinetic and pharmacodynamic effects in the bloodstream, presence and persistence of peak action, and within-subject variability in the glucose-lowering response. The currently available data show that basal insulin analogs have a lower risk of hypoglycemia than NPH human insulin, in both type 1 and type 2 diabetes, then excluding additional harmful effects on the cardiovascular system mediated by activation of the adrenergic system. Given that no biological rationale for a possible difference in cardiovascular effect of basal insulins has been proposed so far, available meta-analyses of publicly disclosed randomized controlled trials do not show any signal of increased risk of major cardiovascular events between the different basal insulin analogs. However, the number of available cardiovascular events in these trials is very small, preventing any clear-cut conclusion. The results of an ongoing clinical trial comparing glargine and degludec with regard to cardiovascular safety will provide definitive evidence.

Keywords: basal insulin, cardiovascular effects, long-acting insulin analog, cardiovascular risk

\section{Introduction}

Basal insulin is an important component of treatment for both type 1 diabetes (T1DM) and type 2 diabetes (T2DM). In T1DM patients on multiple daily injections, basal insulin is combined with prandial (rapid-acting) insulin in basal-bolus schemes; in T2DM, basal insulin is used either alone or in combination with non-insulin drugs or prandial insulin.

One of the principal aims of treatment in patients with diabetes is the prevention of diabetic complications, including cardiovascular disease. There is some evidence, although controversial, that the attainment of good glycemic control reduces the long-term cardiovascular risk in both $\mathrm{T}_{1} \mathrm{DM}^{1}$ and $\mathrm{T} 2 \mathrm{DM} \mathrm{.}^{2,3}$ It is also possible that glucose-lowering drugs, including insulin, have either beneficial or harmful effects on cardiovascular risk independent of their action on blood glucose. On the other hand, the results of epidemiological studies and clinical trials suggest that hypoglycemia 
could have a negative impact on cardiovascular morbidity and/or mortality. $2,4,5$

The aim of this review is to provide an overview of the potential cardiovascular effects of the different available preparations of basal insulin.

\section{Clinical pharmacology of basal insulins}

Current basal insulin (neutral protamine Hagedorn [NPH]) and basal insulin analogs (glargine [IGla], detemir [IDet], and the more recent degludec [IDeg]) differ essentially by various measures of pharmacokinetic and pharmacodynamic effects in the bloodstream, presence and persistence of peak action, and within-subject variability in the glucose-lowering response (Table 1).

NPH consists of a crystalline suspension of human insulin with protamine and zinc. This combination determined an intermediate-acting insulin with a slower onset of action and a longer duration of activity with respect to regular insulin. ${ }^{6}$ Conversely, insulin analogs are synthesized with DNA recombinant technology and have some chemical modifications with respect to natural insulin, resulting in an altered pharmacokinetic profile:

1. In IGla, asparagine at position 21 in the A subunit is replaced with glycine and the carboxyl terminus of the $\mathrm{B}$ subunit has two additional arginines. These modifications determine a different isoelectric point, making the molecule less soluble at normal $\mathrm{pH}$, resulting in slower absorption. $^{7}$

2. IDet is an acylated human insulin that has slower absorption in the bloodstream and binds to circulating albumin, thus having a longer duration of action than regular human insulin. ${ }^{8}$

3. The protein sequence of IDeg differs from that of human insulin for the acylation DesB30 at the amino group of LysB29 with hexadecanedioic acid via a gamma-glutamic acid linker. IDeg forms multihexamers after subcutaneous injection, resulting in a soluble depot with slow and continuous absorption into the circulation. ${ }^{9}$ IDeg reaches

Table I Pharmacokinetic parameters for basal insulin preparations

\begin{tabular}{llll}
\hline Insulin & $\begin{array}{l}\text { Onset of } \\
\text { action (hours) }\end{array}$ & $\begin{array}{l}\text { Peak } \\
\text { (hours) }\end{array}$ & $\begin{array}{l}\text { Duration of } \\
\text { action (hours) }\end{array}$ \\
\hline Regular basal NPH & $1-3$ & $4-8$ & $13-18$ \\
Glargine & $2-4$ & None & $>24$ \\
Detemir & $1-2$ & None & $\begin{array}{l}6-24 \\
\text { (dose-dependent) } \\
\text { Degludec }\end{array}$ \\
\hline
\end{tabular}

Abbreviation: NPH, neutral protamine Hagedorn. steady state after 3 days of administration in a once-daily scheme. The duration of action of IDeg is longer, and the day-to-day variability of absorption is less in comparison with any other basal insulin. ${ }^{10}$

\section{Clinical trials comparing basal insulins Glargine versus NPH}

Nine randomized controlled trials (RCTs) have compared the efficacy of IGla and NPH in T1DM. Despite the fact that in all trials both insulins were titrated aiming at optimal glucose control, IGla was associated with an improvement of fasting plasma glucose in most studies, ${ }^{11-14}$ although not all, ${ }^{15}$ whereas glycated hemoglobin was slightly improved ${ }^{11,12}$ or unchanged. ${ }^{13,14,16}$ Interestingly, despite the trend toward improved glucose control, IGla was not associated with an increased risk of hypoglycemia; ${ }^{17}$ in contrast, some trials reported a reduction in nocturnal hypoglycemia. ${ }^{11,12,14,16}$

A larger number of trials have investigated the effect of IGla versus that of NPH in T2DM. ${ }^{18}$ Most were designed as treat-to-target trials, in which both insulins were titrated to reach strict control of fasting plasma glucose. When added to oral hypoglycemic drugs without prandial insulin, IGla showed a lower incidence of nocturnal hypoglycemia than $\mathrm{NPH}$, with similar overall glucose control. ${ }^{19-22}$ A similar reduction of hypoglycemic risk was observed in trials in which basal insulin was combined with prandial insulin in $\mathrm{T}_{2} \mathrm{DM}^{23-25}$

\section{Detemir versus NPH}

In T1DM, glycated hemoglobin is either reduced ${ }^{26-28}$ or unchanged ${ }^{29-31}$ with IDet in comparison with NPH insulin; such improvement, when present, appears to be due to lower levels of fasting plasma glucose. In addition, IDet is associated with a reduced risk of hypoglycemia. ${ }^{26-31}$ Furthermore, all RCTs are concordant in showing a significant difference in weight gain in patients with T1DM on IDet, with a mean weight reduction ranging between $0.5 \mathrm{~kg}$ and $1.7 \mathrm{~kg}$ versus NPH. A similar reduction in hypoglycemic risk and weight gain was observed in poorly controlled insulin-naïve T2DM patients on oral antidiabetic drug therapy where IDet and NPH insulin were added to their oral therapy, ${ }^{32,33}$ or when IDet and NPH were combined with prandial insulin in patients already treated with insulin. ${ }^{34-36}$

\section{Detemir versus glargine}

In a euglycemic glucose clamp study, IDet was associated with lower within-subject variability in comparison 
with IGla. ${ }^{37}$ This difference could provide an explanation for the observed reduction of nocturnal and severe hypoglycemia with IDet compared with IGla in a 26-week trial in T1DM. ${ }^{38}$ However, this difference could also be due to the fact that fewer patients on IDet reached the predefined target fasting plasma glucose level ( $<126 \mathrm{mg} / \mathrm{dL})$. In addition, more subjects needed twice-daily administration of basal insulin in the IDet group than in the IGla group. In T2DM patients, IDet and IGla provided similar results with regard to glucose control and hypoglycemic risk, the only detectable differences being for weight gain (lower with IDet) and insulin dose (lower with IGla). ${ }^{39-43}$

\section{Degludec versus glargine}

Due to its longer duration of action and lesser day-to-day variability in insulin absorption, IDeg has a potentially lower risk of hypoglycemia than other existing basal insulins. ${ }^{44}$ The incidence of nocturnal hypoglycemia is lower with IDeg than with IGla in both T1DM ${ }^{45-47}$ and T2DM. ${ }^{48-51}$ Meta-analyses of available trials suggest that, in T2DM, IDeg could also be associated with a reduction in the overall incidence of hypoglycemia and with a small improvement of fasting plasma glucose in comparison with IGla, with no difference in weight gain and a modest reduction of insulin doses. ${ }^{52-54}$

\section{Degludec versus detemir}

IDeg and IDet were directly compared in only two studies, both in T1DM, which showed a lower risk of nocturnal hypoglycemia and a greater weight gain with IDeg. ${ }^{55}$

\section{Cardiovascular safety of insulin Molecular mechanisms}

Insulin receptors are widely represented on the surface of cells lining the vascular walls. The binding of insulin to insulin receptors triggers its phosphorylation and activation via intrinsic kinase activity, leading to tyrosine phosphorylation of insulin receptor substrate proteins and to activation of the phosphatidylinositol 3-kinase-Akt pathway, which activates endothelial nitric oxide (NO) synthase (eNOS). ${ }^{56}$ The NO produced by eNOS decreases vascular tone and vascular smooth muscle cell proliferation and diminishes adhesion of inflammatory cells and platelet aggregation at the endothelium. Insulin also increases eNOS phosphorylation in human endothelial cells, improving eNOS activity and significantly reducing the production of reactive oxygen species. Furthermore, insulin modulates production of prostaglandins and endothelium-derived hyperpolarizing factors, which play a critical role as additional active vasodilators. ${ }^{57}$
In addition to vasodilation, insulin can promote vasoconstriction via activation of the mitogen-activated protein kinase (MAPK) cascade, which modulates insulin vasoconstriction and cell growth.

These effects of insulin are mediated, at least in part, by endothelin-1 and the vascular tissue renin-angiotensinaldosterone system. The balance between the proatherogenic and antiatherogenic effects of insulin showed significant differences based on the experimental model. In healthy individuals, insulin exerts a preponderance of vasodilatory and vasoprotective actions, but in insulin-resistant conditions, the opposite vasoconstrictive effects seem to prevail ${ }^{58}$ (Figure 1).

\section{Epidemiological studies}

There is ongoing debate on the cardiovascular safety of insulin analogs. Epidemiological studies show a higher incidence of cardiovascular events in insulin-treated T2DM patients in comparison with those treated with non-insulin drugs. ${ }^{59,60}$ However, observational data do not allow causal inferences. In fact, patients receiving insulin are usually different from those treated with other glucose-lowering drugs; in most studies, they are older, have a longer duration of diabetes, and show a greater burden of complications and comorbidities. All these confounders can be adjusted for in statistical analysis; however, the possibility that insulin treatment is a marker of greater severity of disease, which cannot be accounted for in statistical analysis, cannot be ruled out. For these reasons, assessment of the cardiovascular safety of insulin should be based on RCTs.

\section{Clinical trials}

To date, few intervention studies have evaluated the longterm effects of insulin treatment in T2DM and included

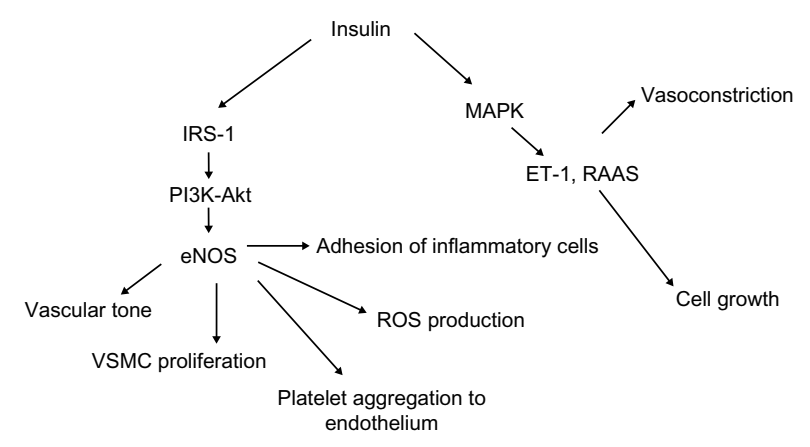

Figure I Cardiovascular effects of insulin: molecular mechanisms.

Abbreviations: Akt, Protein kinase B; IRS, insulin receptor substrate; PI3K, phosphatidylinositol 3-kinase; eNOS, endothelial nitric oxide synthase; MAPK, mitogen-activated protein kinase; VSMC, vascular smooth muscle cell; ROS, reactive oxygen species; ET-I, endothelin-I; RAAS, renin-angiotensin-aldosterone system. 
major cardiovascular events among their principal endpoints. DIGAMI (Diabetes Mellitus Insulin Glucose Infusion in Acute Myocardial Infarction) is an RCT comparing intensified insulin with standard care in patients with myocardial infarction. In this study, insulin produced a remarkable reduction of mortality, with a 2.3-year longer survival time at 20 -year follow-up. ${ }^{61}$ However, the possibility that the reduction in mortality was determined by improved glucose control, rather than by a glucose-independent effect of insulin itself, should be considered. In addition, in the DIGAMI trial, intensified insulin treatment was initiated on hospital admission for myocardial infarction and maintained throughout follow-up; therefore, the design of the trial did not allow discrimination of whether the benefits were due to intensified treatment in the acute or chronic phase. A subsequent trial designed to elucidate this specific point, DIGAMI-2, failed in its objective, because the different treatment groups showed similar glucose control despite different glycemic targets. However, in an epidemiological analysis of this study, those receiving insulin showed a significant increase in non-fatal cardiovascular events (odds ratio 1.89, 95\% confidence interval $1.35-2.63, P=0.0002) .{ }^{62}$

Some further information can be obtained from the BARI-2D (Bypass Angioplasty Revascularization Investigation 2 Diabetes) study, which compared an insulin-providing (insulin and/or sulfonylureas) and an insulin-sensitizing (metformin and/or thiazolidinedione) regimen for glucose control in T2DM patients affected by ischemic heart disease. Five-year cardiovascular mortality and myocardial infarction rates did not differ significantly between the two treatment groups, with a small advantage for insulin sensitizers only in those undergoing coronary heart bypass grafting. ${ }^{63}$ Again, interpretation of results is problematic, because the other drugs used in the trial besides insulin could have either detrimental (sulfonylureas, ${ }^{64}$ thiazolidinediones ${ }^{65}$ ) or beneficial (metformin ${ }^{66}$ ) effects on cardiovascular risk.

In patients without prior cardiovascular events and at lower risk, the UK Prospective Diabetes Study failed to detect any significant benefit of insulin during the core phase of the trial, ${ }^{67}$ reaching a statistically significant reduction in the incidences of myocardial infarction and cardiovascular mortality in a subsequent 10 -year follow-up. ${ }^{68}$ The trial was designed to verify the effect on all diabetic complications (microvascular plus macrovascular) of intensified glucose control obtained with different drugs (insulin, sulfonylureas, or metformin); therefore, the study was underpowered for the specific aim of assessing the cardiovascular effects of insulin.
In addition, differences in outcomes could be due to divergent patterns of glucose control rather than to specific effects of each drug. When comparing insulin with other intensified treatments, cardiovascular morbidity and mortality rates were higher than with metformin, and not different from those with sulfonylureas. ${ }^{4}$

More recently, in the ORIGIN (Outcome Reduction with Initial Glargine Intervention) trial, IGla failed to show any cardiovascular harm or benefit over the comparator (no therapy or oral drugs) in patients with recent-onset diabetes and high cardiovascular risk. These results suggest that, from a cardiovascular standpoint, insulin treatment is neutral. However, the doses of IGla administered in this trial were rather low (with a median reaching $0.4 \mathrm{U} / \mathrm{kg}$ * day after 6 years in the $80 \%$ of patients still on treatment). Consequently, these results cannot exclude either beneficial or detrimental cardiovascular effects at higher doses. ${ }^{69}$

One of the main side effects of insulin therapy is hypoglycemia, which could be associated with an increase in cardiovascular risk. Experimental studies suggest that hypoglycemia may induce abnormal myocardial repolarization, QT prolongation, ventricular arrhythmias, and myocardial ischemia, probably mediated by adrenergic activation. ${ }^{70}$ Epidemiological studies and exploratory analyses of trials supported the link between hypoglycemic events and cardiovascular outcomes. ${ }^{2,4,5}$ Notably, in the ACCORD (Action to Control Cardiovascular Risk in Diabetes) trial, ${ }^{71}$ an aggressive approach to glucose control, with wide use of insulin and a high incidence of severe hypoglycemia, identified increased cardiovascular mortality, suggesting that aggressive management of hyperglycemia could lead to an increase in cardiovascular mortality.

\section{Cardiovascular safety of basal insulin analogs Molecular mechanisms}

The mechanism of action of insulin analogs is identical to that of human insulin, ie, they bind to the same receptor, producing the same cascade of intracellular signaling. The binding affinity for the insulin receptor significantly decreases from IGla and its metabolite, M1 (80\%), to IDet (46\%) and IDeg (14\%). ${ }^{72}$ A study by Sciacca et al in three engineered cell models reported that basal insulin analogs, ie, IDet and IGla, produced a phosphorylation of both insulin receptor-A and insulin receptor-B similar to human insulin. However, significant differences were observed in intracellular signaling properties, with a higher extracellular-signal-regulated kinase (ERK)/Akt ratio with insulin analogs. ${ }^{73}$ 
IGla induced phosphorylation of MAPK in a dosedependent manner, comparable with that seen for human insulin, and demonstrated a comparable maximal response in many in vitro experimental studies while IDet-stimulated MAPK phosphorylation was substantially lower. The reduced phosphorylation of MAPK induced by IDet compared with IGla was more marked in L6 myocytes and vascular smooth muscle cells than in 3T3-L1 adipocytes, thus suggesting potential differences with regard to cardiovascular effects. ${ }^{74}$

\section{Clinical trials on glargine and detemir}

Long-acting insulin analogs produce a lower risk of hypoglycemia than NPH human insulin, in both T1DM and T2DM. ${ }^{17,18}$ A Cochrane review of RCTs in T2DM patients revealed that, in comparison with NPH insulin, the risk of severe hypoglycemia was 30\% lower with IGla and 50\% lower with IDet. ${ }^{75}$ If hypoglycemia plays a role in the development of cardiovascular disease, long-acting analogs could have a more favorable cardiovascular risk profile than human NPH insulin. Unfortunately, specific data on cardiovascular effects of long-term treatment with each analog are sparse. Presently, there is no available cardiovascular outcome trial with IDet. The only such study with IGla is the ORIGIN trial, ${ }^{69}$ which was described above. Based on the ORIGIN results, IGla should be considered safe for the cardiovascular system, at least when used at relatively low doses. Unfortunately, in this trial, IGla was compared with non-insulin treatment and not with NPH; therefore, the study does not provide any information on possible differences in cardiovascular effects between IGla and human insulin.

\section{Cardiovascular safety of degludec}

The most recently introduced long-acting analog is IDeg, which appears to be associated with an even lower hypoglycemic risk than glargine. ${ }^{54}$ On February 8, 2013, the US Food and Drug Administration (FDA) denied approval for IDeg ${ }^{76}$ in contrast with a previous decision of the European Medicines Agency, ${ }^{77}$ because of an increased risk (estimated hazard ratio $1.29,95 \%$ confidence interval $0.88-1.88$ ) of a composite endpoint including cardiovascular death, non-fatal myocardial infarction, non-fatal stroke, and unstable angina, relative to comparators. In the updated FDA composite endpoint analysis of major adverse cardiovascular events, excluding events of unstable angina pectoris, that included all completed trials as of May 1, 2012, incidence rates were 1.41 per 100 events per patient year for IDeg + IDegAsp and 0.90 per 100 events per patient year for the comparator. In addition, if, together with the exclusion of unstable angina pectoris events, all major adverse cardiovascular events reported up to 30 days after drug discontinuation were included, the estimated hazard ratio for IDeg + IDegAsp versus comparators was 1.61 (95\% confidence interval 0.99-2.6). The decision contrasted with the FDA Endocrinologic and Metabolic Drugs Advisory Committee, which in November 2012 had unanimously recommended approval of the drug, although suggesting a post-approval cardiovascular outcomes trial. Available meta-analyses of publicly disclosed RCTs did not show any signal of increased risk of major cardiovascular events with IDeg in comparison with IGla. ${ }^{54}$ The number of available cardiovascular events in trials with IDeg is very small, preventing any clear-cut conclusion. Notably, the analyses performed by the FDA, which diverged from the predefined analysis plans used for other approved diabetes drugs, achieved statistical significance only when using a very peculiar definition of cardiovascular events, ie, excluding unstable angina. In addition, in order to obtain a significant result, events occurred after drug discontinuation had to be included: since the duration of the trials is quite short, the difference in cardiovascular effects between IDeg and other basal insulins cannot reasonably be attributed to a differential action on long-term atherogenesis; on the other hand, if some immediate cardiovascular harm is hypothesized, the inclusion of events after drug discontinuation is difficult to justify.

The iteration of statistical analyses leads, sooner or later, to a "significant" result. In fact, statistical significance was reached only after excluding unstable angina from major cardiovascular events and including cases that occurred during post-trial follow-up, when patients had returned to their previous basal insulin (usually glargine). It should also be considered that no biological rationale for a possible difference in cardiovascular effect of basal insulins has ever been proposed so far. The results of the FDA analysis could be the effect of chance. At the same time, it is important to have an accurate assessment of the cardiovascular safety of newer agents. A trial comparing the incidence of major cardiovascular events during therapy with insulin IDeg versus IGla in T2DM individuals at high risk of cardiovascular events (DEVOTE; NCT01959529) ${ }^{78}$ is currently ongoing; its results, expected a few years from now, will provide definitive evidence on the cardiovascular safety of IDeg.

\section{Conclusion}

After about nine decades since its first clinical use, the longterm cardiovascular effect of insulin is still partly unknown, at least in T2DM. The introduction of insulin analogs 
complicates the issue, as those molecules could have, at least theoretically, cardiovascular effects different from those of human insulin. A wide range of experimental studies, while adding knowledge and insight on the molecular mechanisms of the action of insulin at the vascular level, do not allow any reliable prediction regarding the clinical effects of insulin and its analogs on cardiovascular risk.

In conclusion, although insulin is one of the most widely used drugs for the treatment of diabetes, we still need more data from clinical trials. Results of randomized studies comparing different analogs, such as in the ongoing DEVOTE trial, ${ }^{78}$ will provide information on which molecule has to be preferred as a basal insulin. However, we are still missing data assessing the effect of insulin on the incidence of cardiovascular events in comparison with other active drugs for T2DM. Such a trial, although not required by regulatory authorities, could be of great relevance in the definition of treatment algorithms for type 2 diabetes.

\section{Disclosure}

The authors report no conflicts of interest in this work.

\section{References}

1. Writing Team for the Diabetes Control and Complications Trial/ Epidemiology of Diabetes Interventions and Complications Research Group. Sustained effect of intensive treatment of type 1 diabetes mellitus on development and progression of diabetic nephropathy: the Epidemiology of Diabetes Interventions and Complications (EDIC) study. JAMA. 2003;290:2159-2167.

2. Monami M, Adalsteinsson JE, Desideri CM, Ragghianti B, Dicembrini I, Mannucci E. Fasting and post-prandial glucose and diabetic complication. A meta-analysis. Nutr Metab Cardiovasc Dis. 2013;23: 591-598.

3. Ray KK, Seshasai SR, Wijesuriya S, et al. Effect of intensive control of glucose on cardiovascular outcomes and death in patients with diabetes mellitus: a meta-analysis of randomised controlled trials. Lancet. 2009;373:1765-1772.

4. Yakubovich N, Gerstein HC. Serious cardiovascular outcomes in diabetes: the role of hypoglycemia. Circulation. 2011;123:342-348.

5. Zoungas S, Patel A, Chalmers J, et al. Severe hypoglycemia and risks of vascular events and death. N Engl J Med. 2010;363:1410-1418.

6. Yki-Järvinen H. Combination therapy with insulin and oral agents: optimizing glycemic control in patients with type 2 diabetes mellitus. Diab Metab Res Rev. 2002;3:S77-S81.

7. Vague P, Selam JR, Skeie S. Insulin detemir is associated with more predictable glycemic control and reduced risk of hypoglycemia than NPH insulin in patients with type 1 diabetes on a basal-bolus regimen with premeal insulin aspart. Diabetes Care. 2003;26:590-596.

8. Kurtzhals P. Engineering predictability and protraction in a basal insulin analogue: the pharmacology of insulin detemir. Int J Obes Relat Metab Disord. 2004;28:S23-S28.

9. Jonassen I, Havelund S, Hoeg-Jensen T, Steensgaard DB, Wahlund PO, Ribel U. Design of the novel protraction mechanism of insulin degludec, an ultra-long-acting basal insulin. Pharm Res. 2012;29:2104-2014.

10. Haahr H, Heise T. A review of the pharmacological properties of insulin degludec and their clinical relevance. Clin Pharmacokinet. 2014;53: $787-800$.
11. Rossetti P, Pampanelli S, Fanelli C, et al. Intensive replacement of basal insulin in patients with type 1 diabetes given rapid-acting insulin analog at mealtime: a 3-month comparison between administration of NPH insulin four times daily and glargine insulin at dinner or bedtime. Diabetes Care. 2003;26:1490-1496.

12. Porcellati F, Rossetti P, Pampanelli S, et al. Better long-term glycaemic control with the basal insulin glargine as compared with NPH in patients with type 1 diabetes mellitus given meal-time lispro insulin. Diabet Med. 2004;21:1213-1220.

13. Raskin P, Klaff L, Bergenstal R, Hallé JP, Donley D, Mecca T. A 16-week comparison of the novel insulin analog insulin glargine (HOE 901) and NPH human insulin used with insulin lispro in patients with type 1 diabetes. Diabetes Care. 2000;23:1666-1671.

14. Ratner RE, Hirsch IB, Neifing JL, Garg SK, Mecca TE, Wilson CA. Less hypoglycemia with insulin glargine in intensive insulin therapy for type 1 diabetes. US Study Group of Insulin Glargine in Type 1 Diabetes. Diabetes Care. 2000;23:639-643.

15. Home PD, Rosskamp R, Forjanic-Klapproth J, Dressler A; European Insulin Glargine Study Group. A randomized multicentre trial of insulin glargine compared with NPH insulin in people with type 1 diabetes. Diabetes Metab Res Rev. 2005;21:545-553.

16. Bolli GB, Songini M, Trovati M, et al. Lower fasting blood glucose, glucose variability and nocturnal hypoglycaemia with glargine vs NPH basal insulin in subjects with type 1 diabetes. Nutr Metab Cardiovasc Dis. 2009;19:571-579.

17. Monami M, Marchionni N, Mannucci E. Long-acting insulin analogues vs NPH human insulin in type 1 diabetes. A meta-analysis. Diabetes Obes Metab. 2009;11:372-378.

18. Monami M, Marchionni N, Mannucci E. Long-acting insulin analogues versus NPH human insulin in type 2 diabetes: a meta-analysis. Diabetes Res Clin Pract. 2008;81:184-189.

19. Yki-Järvinen H, Dressler A, Ziemen M; HOE 901/300s Study Group. Less nocturnal hypoglycemia and better post-dinner glucose control with bedtime insulin glargine compared with bedtime NPH insulin during insulin combination therapy in type 2 diabetes. HOE 901/3002 Study Group. Diabetes Care. 2000;23:1130-1136.

20. Massi Benedetti M, Humburg E, Dressler A, Ziemen M. A one-year, randomised, multicentre trial comparing insulin glargine with NPH insulin in combination with oral agents in patients with type 2 diabetes. Horm Metab Res. 2003;35:189-196.

21. Fritsche A, Schweitzer MA, Häring HU; 4001 Study Group. Glimepiride combined with morning insulin glargine, bedtime neutral protamine Hagedorn insulin, or bedtime insulin glargine in patients with type 2 diabetes. A randomized, controlled trial. Ann Intern Med. 2003;138: 952-959.

22. Riddle MC, Rosenstock J, Gerich J; Insulin Glargine 4002 Study Investigators. The treat-to-target trial: randomized addition of glargine or human NPH insulin to oral therapy of type 2 diabetic patients. Diabetes Care. 2003;26:3080-3086.

23. Rosenstock J, Schwartz SL, Clark CM Jr, Park GD, Donley DW, Edwards MB. Basal insulin therapy in type 2 diabetes: 28-week comparison of insulin glargine (HOE 901) and NPH insulin. Diabetes Care. 2001;24:631-636.

24. Rosenstock J, Dailey G, Massi-Benedetti M, Fritsche A, Lin Z, Salzman A. Reduced hypoglycemia risk with insulin glargine: a metaanalysis comparing insulin glargine with human NPH insulin in type 2 diabetes. Diabetes Care. 2005;28:950-955.

25. Fonseca V, Bell DS, Berger S, Thomson S, Mecca TE. A comparison of bedtime insulin glargine with bedtime neutral protamine Hagedorn insulin in patients with type 2 diabetes: subgroup analysis of patients taking once-daily insulin in a multicenter, randomized, parallel group study. Am J Med Sci. 2004;328:274-280.

26. Bartley PC, Bogoev M, Larsen J, Philotheou A. Long-term efficacy and safety of insulin detemir compared to neutral protamine Hagedorn insulin in patients with type 1 diabetes using a treat-to-target basal-bolus regimen with insulin aspart at meals: a 2-year, randomized, controlled trial. Diabet Med. 2008;25:442-449. 
27. Home P, Bartley P, Russell-Jones D, et al; Study to Evaluate the Administration of Detemir Insulin Efficacy, Safety and Suitability (STEADINESS) Study Group. Insulin detemir offers improved glycemic control compared with NPH insulin in people with type 1 diabetes: a randomized clinical trial. Diabetes Care. 2004;27:1081-1087.

28. Hermansen K, Fontaine P, Kukolja KK, Peterkova V, Leth G, Gall MA. Insulin analogues (insulin detemir and insulin aspart) versus traditional human insulins (NPH insulin and regular human insulin) in basal-bolus therapy for patients with type 1 diabetes. Diabetologia. 2004:47:622-629.

29. Pieber TR, Draeger E, Kristensen A, Grill V. Comparison of three multiple injection regimens for type 1 diabetes: morning plus dinner or bedtime administration of insulin detemir vs morning plus bedtime NPH insulin. Diabet Med. 2005;22:850-857.

30. Standl E, Lang H, Roberts A. The 12-month efficacy and safety of insulin detemir and NPH insulin in basal-bolus therapy for the treatment of type 1 diabetes. Diabetes Technol Ther. 2004;6:579-588.

31. Kølendorf K, Ross GP, Pavlic-Renar I, et al. Insulin detemir lowers the risk of hypoglycaemia and provides more consistent plasma glucose levels compared with NPH insulin in type 1 diabetes. Diabet Med. 2006;23:729-735.

32. Hermansen K, Davies M, Derezinski T, Martinez Ravn G, Clauson P, Home P. A 26-week, randomized, parallel, treat-to-target trial comparing insulin detemir with NPH insulin as add-on therapy to oral glucoselowering drugs in insulin-naive people with type 2 diabetes. Diabetes Care. 2006;29:1269-1274.

33. Philis-Tsimikas A, Charpentier G, Clauson P, Ravn GM, Roberts VL, Thorsteinsson B. Comparison of once-daily insulin detemir with NPH insulin added to a regimen of oral antidiabetic drugs in poorly controlled type 2 diabetes. Clin Ther. 2006;28:1569-1581.

34. Raslová K, Bogoev M, Raz I, Leth G, Gall MA, Hâncu N. Insulin detemir and insulin aspart: a promising basal-bolus regimen for type 2 diabetes. Diabetes Res Clin Pract. 2004;66:193-201.

35. Haak T, Tiengo A, Draeger E, Suntum M, Waldhäusl W. Lower withinsubject variability of fasting blood glucose and reduced weight gain with insulin detemir compared to NPH insulin in patients with type 2 diabetes. Diabetes Obes Metab. 2005;7:56-64.

36. Fajardo Montañana C, Hernández Herrero C, Rivas Fernández M. Less weight gain and hypoglycaemia with once-daily insulin detemir than NPH insulin in intensification of insulin therapy in overweight type 2 diabetes patients: the PREDICTIVE BMI clinical trial. Diabet Med. 2008;25:916-923.

37. Heise T, Nosek L, Rønn BB, et al. Lower within-subject variability of insulin detemir in comparison to NPH insulin and insulin glargine in people with type 1 diabetes. Diabetes. 2004;53:1614-1620.

38. Pieber TR, Treichel HC, Hompesch B, et al. Comparison of insulin detemir and insulin glargine in subjects with type 1 diabetes using intensive insulin therapy. Diabet Med. 2006;24:635-642.

39. Rosenstock J, Davies M, Home PD, Larsen J, Koenen C, Schernthaner G. A randomised, 52-week, treat-to-target trial comparing insulin detemir with insulin glargine when administered as add-on to glucose-lowering drugs in insulin-naïve people with type 2 diabetes. Diabetologia. 2008;51:408-416.

40. Swinnen SG, Dain MP, Aronson R, et al. A 24-week, randomized, treatto-target trial comparing initiation of insulin glargine once-daily with insulin detemir twice-daily in patients with type 2 diabetes inadequately controlled on oral glucose-lowering drugs. Diabetes Care. 2010;33: 1176-1178.

41. Hollander P, Cooper J, Bregnhøj J, Pedersen CB. A 52-week, multinational, open-label, parallel-group, noninferiority, treat-to-target trial comparing insulin detemir with insulin glargine in a basal-bolus regimen with mealtime insulin aspart in patients with type 2 diabetes. Clin Ther 2008;30:1976-1987.

42. Raskin P, Gylvin T, Weng W, Chaykin L. Comparison of insulin detemir and insulin glargine using a basal-bolus regimen in a randomized, controlled clinical study in patients with type 2 diabetes. Diabetes Metab Res Rev. 2009;25:542-548.
43. Swinnen SG, Simon AC, Holleman F, Hoekstra JB, Devries JH. Insulin detemir versus insulin glargine for type 2 diabetes mellitus. Cochrane Database Syst Rev. 2011;6:532-546.

44. Heise T, Hermanski L, Nosek L, Feldman A, Rasmussen S, Haahr H. Insulin degludec: four times lower pharmacodynamic variability than insulin glargine under steady-state conditions in type 1 diabetes. Diabetes Obes Metab. 2012;14:859-864.

45. Heller S, Buse J, Fisher M, et al; BEGIN Basal-Bolus Type 1 Trial Investigators. Insulin degludec, an ultra-long acting basal insulin, versus insulin glargine in basal-bolus treatment with mealtime insulin aspart in type 1 diabetes (BEGIN Basal-Bolus Type 1): a phase 3 , randomised, open-label, treat-to-target non-inferiority trial. Lancet. 2012;21:1489-1497.

46. Mathieu C, Hollander P, Miranda-Palma B, et al; NN1250-3770 (BEGIN: Flex T1) Trial Investigators. Efficacy and safety of insulin degludec in a flexible dosing regimen vs insulin glargine in patients with type 1 diabetes (BEGIN: Flex T1): a 26-week randomized, treatto-target trial with a 26-week extension. $J$ Clin Endocrinol Metab. 2013;98:1154-1162

47. Bode BW, Buse JB, Fisher M, et al; BEGIN ${ }^{\circledR}$ Basal-Bolus Type 1 trial investigators. Insulin degludec improves glycaemic control with lower nocturnal hypoglycaemia risk than insulin glargine in basal-bolus treatment with mealtime insulin aspart in Type 1 diabetes (BEGIN $\left({ }^{\circledR}\right)$ Basal-Bolus Type 1): 2-year results of a randomized clinical trial. Diabet Med. 2013;30:1293-1297.

48. Zinman B, Philis-Tsimikas A, Cariou B, et al; NN1250-3579 (BEGIN Once Long) Trial Investigators. Insulin degludec versus insulin glargine in insulin-naive patients with type 2 diabetes: a 1-year, randomized, treat-to-target trial (BEGIN Once Long). Diabetes Care. 2012;35: 2464-2471.

49. Gough SC, Bhargava A, Jain R, Mersebach H, Rasmussen S, Bergenstal RM. Low-volume insulin degludec 200 units $/ \mathrm{mL}$ once daily improves glycemic control similarly to insulin glargine with a low risk of hypoglycemia in insulin-naive patients with type 2 diabetes: a 26-week, randomized, controlled, multinational, treat-to-target trial: the BEGIN LOW VOLUME trial. Diabetes Care. 2013;36: 2536-2542.

50. Rodbard HW, Cariou B, Zinman B, et al; BEGIN Once Long Trial Investigators. Comparison of insulin degludec with insulin glargine in insulin-naive subjects with type 2 diabetes: a 2-year randomized, treat-to-target trial. Diabet Med. 2013;30:1298-1304.

51. Garber AJ, King AB, Del Prato S, et al; NN1250-3582 (BEGIN BB T2D) Trial Investigators. Insulin degludec, an ultra-long acting basal insulin, versus insulin glargine in basal-bolus treatment with mealtime insulin aspart in type 2 diabetes (BEGIN Basal-Bolus Type 2): a phase 3, randomised, open-label, treat-to-target non-inferiority trial. Lancet. 2012;379:1498-1507.

52. Vora J, Christensen T, Rana A, Bain SC. Insulin degludec versus insulin glargine in type 1 and type 2 diabetes mellitus: a meta-analysis of endpoints in Phase 3a trials. Diabetes Ther. 2014;5:435-446.

53. Ratner RE, Gough SC, Mathieu C, et al. Hypoglycaemia risk with insulin degludec compared with insulin glargine in type 2 and type 1 diabetes: a pre-planned meta-analysis of phase 3 trials. Diabetes Obes Metab. 2013;15:175-184.

54. Monami M, Mannucci E. Efficacy and safety of degludec insulin: a meta-analysis of randomised trials. Curr Med Res Opin. 2013;29: 339-342.

55. Hirsch IB, Bode B, Courreges JP, et al. Insulin degludec/insulin aspart administered once daily at any meal, with insulin aspart at other meals versus a standard basal-bolus regimen in patients with type 1 diabetes: a 26-week, phase 3, randomized, open-label, treat-to-target trial. Diabetes Care. 2012;35:2174-2181.

56. Muniyappa R, Yavuz S. Metabolic actions of angiotensin II and insulin: a microvascular endothelial balancing act. Mol Cell Endocrinol. 2012;378:59-69.

57. Manrique C, Lastra G, Sowers JR. New insights into insulin action and resistance in the vasculature. Ann NY Acad Sci. 2014;1311:138-150. 
58. Potenza MA, Addabbo F, Montagnani M. Vascular actions of insulin with implications for endothelial dysfunction. Am J Physiol Endocrinol Metab. 2009;297:E568-E577.

59. Roumie CL, Greevy RA, Grijalva CG, et al. Association between intensification of metformin treatment with insulin vs sulfonylureas and cardiovascular events and all-cause mortality among patients with diabetes. JAMA. 2014;311:2288-2296.

60. Currie CJ, Poole CD, Evans M, Peters JR, Morgan CL. Mortality and other important diabetes-related outcomes with insulin vs other antihyperglycemic therapies in type 2 diabetes. J Clin Endocrinol Metab. 2013;98:668-677.

61. Ritsinger V, Malmberg K, Mårtensson A, Rydén L, Wedel H, Norhammar A. Intensified insulin-based glycaemic control after myocardial infarction: mortality during 20 year follow-up of the randomised Diabetes Mellitus Insulin Glucose Infusion in Acute Myocardial Infarction (DIGAMI 1) trial. Lancet Diabetes Endocrinol. 2014;2: 627-633.

62. Mellbin LG, Malmberg K, Norhammar A, Wedel H, Rydén L; DIGAMI 2 Investigators. Prognostic implications of glucose-lowering treatment in patients with acute myocardial infarction and diabetes: experiences from an extended follow-up of the Diabetes Mellitus Insulin-Glucose Infusion in Acute Myocardial Infarction (DIGAMI) 2 Study. Diabetologia. 2011;54:1308-1317.

63. Chaitman BR, Hardison RM, Adler D, et al; Bypass Angioplasty Revascularization Investigation 2 Diabetes (BARI 2D) Study Group. The Bypass Angioplasty Revascularization Investigation 2. Diabetes randomized trial of different treatment strategies in type 2 diabetes mellitus with stable ischemic heart disease: impact of treatment strategy on cardiac mortality and myocardial infarction. Circulation. 2009;120: 2529-2540.

64. Monami M, Genovese S, Mannucci E. Cardiovascular safety of sulfonylureas: a meta-analysis of randomized clinical trials. Diabetes Obes Metab. 2013;15:938-953.

65. Lago RM, Singh PP, Nesto RW. Congestive heart failure and cardiovascular death in patients with prediabetes and type 2 diabetes given thiazolidinediones: a meta-analysis of randomised clinical trials. Lancet. 2007;370:1129-1136.

66. Lamanna C, Monami M, Marchionni N, Mannucci E. Effect of metformin on cardiovascular events and mortality: a meta-analysis of randomized clinical trials. Diabetes Obes Metab. 2011;13:221-228.

67. [No authors listed]. Intensive blood-glucose control with sulphonylureas or insulin compared with conventional treatment and risk of complications in patients with type 2 diabetes (UKPDS 33). UK Prospective Diabetes Study (UKPDS) Group. Lancet. 1998;352: $837-853$.
68. Holman RR, Paul SK, Bethel MA, Matthews DR, Neil HA. 10-year follow-up of intensive glucose control in type 2 diabetes. $N$ Engl J Med. 2008;359:1577-1589.

69. Gerstein HC, Bosch J, Dagenais GR, et al; ORIGIN Trial Investigators. Basal insulin and cardiovascular and other outcomes in dysglycemia. N Engl J Med. 2012;367:319-328.

70. Frier BM, Schernthaner G, Heller SR. Hypoglycemia and cardiovascular risks. Diabetes Care. 2011;34:S132-S137.

71. Gerstein HC, Miller ME, Byington RP, et al. Effects of intensive glucose lowering in type 2 diabetes. $N$ Engl J Med. 2008;358:2545-2559.

72. Tennagels N, Werner U. The metabolic and mitogenic properties of basal insulin analogues. Arch Physiol Biochem. 2013;119:1-14.

73. Sciacca L, Cassarino MF, Genua M, et al. Insulin analogues differently activate insulin receptor isoforms and post-receptor signalling. Diabetologia. 2010;53:1743-1753.

74. Wada T, Azegami M, Sugiyama M, Tsuneki H, Sasaoka T. Characteristics of signalling properties mediated by long-acting insulin analogue glargine and detemir in target cells of insulin. Diabetes Res Clin Pract. 2008;81:269-277.

75. Horvath $\mathrm{K}$, Jeitler $\mathrm{K}$, Berghold A, et al. Long-acting insulin analogues versus NPH insulin (human isophane insulin) for type 2 diabetes mellitus. Cochrane Database Syst Rev. 2007;2:CD005613.

76. Novo Nordisk. Novo Nordisk receives complete response letter in the US for Tresiba ${ }^{\circledR}$ and Ryzodeg ${ }^{\circledR}$. Available from: http://www.novonordisk.com/ include/asp/exe_news_attachment.asp?sAttachmentGUID=837000600ce3-4577-a35a-f3e57801637d. Accessed January 13, 2015.

77. CHMP assessment report; Tresiba; International non-proprietary name: insulin degludec. European Medicines Agency; 2012. Available from: http://www.ema.europa.eu/docs/en_GB/document_library/ EPAR_-_Public_assessment_report/human/002498/WC500139010. pdf. Accessed January 13, 2015.

78. A Trial Comparing Cardiovascular Safety of Insulin Degludec Versus Insulin Glargine in Subjects With Type 2 Diabetes at High Risk of Cardiovascular Events (DEVOTE). ClinicalTrials.gov; US National Institutes of Health; updated April 14, 2015. Available from: https:// www.clinicaltrial.gov/ct2/show/NCT01959529?term=devote+deglud ec\&rank=1. Accessed January 13, 2015.
Drug, Healthcare and Patient Safety

\section{Publish your work in this journal}

Drug, Healthcare and Patient Safety is an international, peer-reviewed open-access journal exploring patient safety issues in the healthcare continuum from diagnostic and screening interventions through to treatment, drug therapy and surgery. The journal is characterized by the rapid reporting of reviews, original research, clinical, epidemiological and

\section{Dovepress}

post-marketing surveillance studies, risk management, health literacy and educational programs across all areas of healthcare delivery. The manuscript management system is completely online and includes a very quick and fair peer-review system. Visit http://www.dovepress.com/ testimonials.php to read real quotes from published authors. 